\title{
Early determinants of right and left ventricular output in ventilated preterm infants
}

\author{
Nick Evans, Martin Kluckow
}

\begin{abstract}
One hundred and twenty ventilated preterm infants, birthweight $<1500 \mathrm{~g}$, were examined within the first 36 hours with colour Doppler echocardiography, to determine the cardiorespiratory influences on right (RVO) and left ventricular output (LVO). Forty nine of these infants had three further daily scans. Measurements included left ventricular (LV) ejection fraction, Doppler determination of RVO and $L V O$, and ductal and interatrial shunt direction, velocity and colour Doppler diameter. Infants were grouped by respiratory disease severity: mild, mean $\mathrm{FIO}_{2}$ in first 24 hours < 0.5 ; moderate/severe, mean $\mathrm{FIO}_{2}<0.5$; and fatal, death resulting directly from acute respiratory distress.
\end{abstract}

In the early studies ventricular outputs varied widely (RVO: 62-412 $\mathrm{ml} / \mathrm{kg} / \mathrm{minute}$, LVO: $75-505 \mathrm{ml} / \mathrm{kg} / \mathrm{minute})$. The incidence of low ventricular outputs $(<150 \mathrm{ml} / \mathrm{kg} /$ minute) increased with worsening respiratory disease. The incidence of low RVO in the mild group was $19 \%$, in the moderate/severe group $42 \%$, and in the fatal group 85\%. More infants had a low RVO than a low LVO, reflecting the impact of ductal shunting. Ductal and atrial shunting was predominantly left to right except in those with fatal respiratory disease. In those studied longitudinally, RVO and LVO increased with age and low outputs were not seen after day 3.

Multilinear regression analyses, with RVO as the dependent variable, revealed increasing LVO and atrial shunt diameter as significant positive influences and increasing ductal shunt diameter and mean airway pressure as a significant negative influence. With LVO as the dependent variable, increasing RVO, ductal shunt diameter, and age were significant positive influences and increasing atrial shunt diameter was a significant negative influence.

Low ventricular outputs are more common with worsening respiratory disease. Mean airway pressure and ductal shunting are two negative influences on ventricular outputs over which there is some therapeutic control.

(Arch Dis Child 1996; 74: F88-F94)

Keywords: cardiac output, ductus arteriosus, respiratory disease, Doppler echocardiography.

Sydney, NSW 2050,

Australia.

Nick Evans

Martin Kluckow

Correspondence to:

Dr Nick Evans

Accepted 21 November 1995 A fundamental aim in intensive care of preterm infants is the maintenance of adequate and stable systemic and pulmonary perfusion. The haemodynamics of the preterm cardiovascular system are complex with the problems of the transitional circulation and changing pulmonary vascular resistance being compounded by an immature myocardium ${ }^{1}$ and shunting across the fetal channels of the ductus arteriosus and foremen ovale. ${ }^{23}$ Such shunting usually diverts blood left to right from the systemic back into the pulmonary circulation. For the ductus arteriosus, such shunting has been shown to 'steal' blood from the systemic circulation ${ }^{4}$; atrial shunting could have a similar effect. Occasionally these shunts are right to left and so divert blood from the pulmonary to the systemic circulation with resultant hypoxaemia. Positive pressure ventilation, often essential to maintain oxygenation, can also compromise cardiac output. ${ }^{5}$

The output from each ventricle will reflect many of these factors and will also depend intricately on the output from the other side; failure or overload at any point within the circuit will influence other parts of the circulation. Doppler echocardiographic study of cardiac output in preterm newborns has usually focused on one point in the circuit, the left ventricular output (LVO), ${ }^{67}$ and has not taken into account other influences, particularly that of atrial shunting and right ventricular output (RVO).

We have recently shown that reasonable estimates of ductal and atrial shunt size can be derived from their respective colour Doppler shunt diameters. ${ }^{2} 3$ In this Doppler echocardiographic study, these correlations are used to examine the cardiovascular and respiratory influences on both RVO and LVO in a group of ventilated preterm infants with the aim of improving our understanding of preterm cardiovascular haemodynamics and the main influences on cardiac output.

\section{Methods}

One hundred and twenty preterm infants, weighing less than $1500 \mathrm{~g}$ and with respiratory problems which required mechanical ventilation for more than 24 hours, were selected for echocardiographic study. The first 49 infants studied had a daily echocardiogram for each of the first four days, these infants were studied for 12 months from March 1992. The next 71 infants were studied once in the first 36 postnatal hours. These infants were studied for 12 months from June 1993. Twenty one eligible infants ( $14 \%$ of total eligible infants) were not studied as neither investigator was available to perform a scan when they were born. 
gestational age of $27 \cdot 3$ weeks, ranging from 24 to 33 weeks, and had a mean birthweight of $993 \mathrm{~g}$, ranging from 512 to $1490 \mathrm{~g}$.

\section{ECHOCARDIOGRAPHIC DATA COLLECTION}

This was performed with an Acuson $128 / \mathrm{XP} 10$ scanner with a $7 \mathrm{MHz}$ transducer incorporating colour flow, pulsed wave, and continuous wave Doppler. The scan was recorded on to videotape and the measurements then taken from the videotape. Structural normality of the heart was established on the initial scan.

\section{$M$-mode measurements}

LV ejection fraction was measured using a standardised method from $\mathrm{M}$-mode echocardiograms taken from the parasternal long axis view. ${ }^{8}$

Pulmonary artery time to peak velocity to ejection time ratio (TPV:RVET)

This was measured in the main pulmonary artery as an index of pulmonary artery pressure. A standard measurement procedure was used and the ratio was averaged from three cardiac cycles. ${ }^{9}$

\section{Right ventricular output ${ }^{10}$}

Pulsed Doppler recordings of the flow at the level of the pulmonary valve were made from the parasternal long axis view, with care taken to minimise the angle of insonation. An average maximum velocity time integral was derived from the area under the curve of five consecutive cardiac cycles, using the incorporated Acuson cardiac software. The heart rate was measured from the peak to peak intervals of the Doppler velocity time signals. The diameter of the pulmonary valve insertion was measured at end systole from a frame by frame videotape analysis of the $2 \mathrm{D}$ parasternal long axis image and was averaged from three to five cardiac cycles.

\section{Ductus arteriosus}

This was imaged from the high left parasternal view. Colour Doppler was set for automatic preprocessing, lowest velocity variance setting, and filters set for maximum range for volume and velocity settings with medium degree of motion discrimination (Acuson 128/XP10 filter setting 3). The colour flow Doppler mapping scale was set to the maximum range of the automatic preprocessing, usually the maximum velocity was between 0.64 to 0.8 $\mathrm{m} / \mathrm{second}$. The gain was set to optimise the colour flow image within the course of the duct and eliminate any peripheral colour interference. When patent, the minimum diameter (the site of maximum constriction) of the colour flow jet within the course of the ductus was measured from a frame by frame analysis of the videotape. End systolic frames with the clearest discrete appearance to the shunt within the duct were used for measurement. ${ }^{3} \mathrm{~A}$ mean was taken from three to five of the best quality cardiac cycles. The shunt was assessed with pulsed and/or continuous wave Doppler with the sample volume in the pulmonary end of the duct. The shunt pattern was classified as left to right, bidirectional, or right to left. When left to right or bidirectional, the peak left to right velocity was measured. When bidirectional, the proportion of the cardiac cycle with right to left shunting was measured as the time of right to left shunting divided by the total length of the cardiac cycle.

\section{Left ventricular output}

The LV outflow tract was imaged from an apical view modified to incorporate the full length of the ascending aorta. ${ }^{11}$ The pulsed Doppler range gate was placed distal to the aortic valve and the angle correction incorporated into the Acuson $128 / \mathrm{XP} 10$ was aligned along the long axis of the ascending aorta. If the angle was more than $20^{\circ}$ the transducer was manoeuvred to further minimise the angle. The flow velocity time signal was recorded and the maximum velocity time integral averaged from five consecutive cardiac cycles. The heart rate was measured from the peak to peak intervals of the Doppler velocity time signals. The internal diameter of the ascending aorta at the site of flow analysis was measured at the end of systole using frame by frame analysis of the $2 \mathrm{D}$ image taken from a parasternal long axis view. This was averaged from three to five cardiac cycles.

\section{Atrial shunting}

The atrial septum was imaged from a subcostal four chamber view and colour flow Doppler mapping of any shunt across the septum was performed. The colour flow Doppler was set up as described in the section on ductal shunting. The peak frequency of the colour scale was usually set at 0.23 or $0.31 \mathrm{~m} /$ seconds, but sometimes higher for high velocity shunts. The gain was increased until the colour flow picture across the atrial septum was optimised and there was no peripheral colour interference. The diameter of the colour flow jet across the septum was measured at the level of the atrial septum. Frame by frame analysis of the videotape was performed until the clearest image of the left to right component of the interatrial shunt was achieved. The diameter was averaged from three to five of the clearest cardiac cycles. ${ }^{2}$ The pulsed Doppler range gate was placed in the interatrial shunt at the level of the atrial septum with the angle correction adjusted along the long axis of the colour flow of the shunt. The velocity time signal of the interatrial flow was recorded. The pattern of flow was classified as left to right, bidirectional, or right to left. When left to right or bidirectional, the peak left to right velocity was measured. When bidirectional, the proportion of the cardiac cycle with right to left shunting was measured as the time of right to left shunting divided by the total length of the cardiac cycle, as described by Hiraishi et al. ${ }^{12}$ When no 
Table 1 Demographic and clinical parameters according to respiratory disease severity

\begin{tabular}{|c|c|c|c|}
\hline & $\begin{array}{l}\text { Mild respiratory } \\
\text { distress } \\
\left(\text { day } 1 \text { mean } \mathrm{FIO}_{2}\right. \\
<0 \cdot 5, n=77)\end{array}$ & $\begin{array}{l}\text { Moderate to severe } \\
\text { respiratory distress } \\
\text { (day } 1 \text { mean } \mathrm{FIO}_{2} \\
>0 \cdot 5, n=36)\end{array}$ & $\begin{array}{l}\text { Fatal respiratory } \\
\text { distress }(n=7)\end{array}$ \\
\hline $\begin{array}{l}\text { Gestation (weeks) } \\
\text { Age at scan (hours) } \\
\text { Mean FIO } \text {, first } 24 \text { hours } \\
\text { Mean blood pressure }\end{array}$ & $\begin{array}{l}27(24-34) \\
20(7-31) \\
0.35(0 \cdot 21-0 \cdot 49)^{\star}\end{array}$ & $\begin{array}{l}27(24-30) \\
19.5(7-27) \\
0.6(0.5-0.84)^{\star}\end{array}$ & $\begin{array}{l}26(24-30) \\
14(5-25) \\
0.89(0.69-0.98)^{\star}\end{array}$ \\
\hline $\begin{array}{l}\text { ( }<36 \text { hours) } \\
\% \text { Given } 5 \% \text { albumin } \\
\text { (m1/kg in first } 24 \text { hours) } \\
\text { Inotropes, first } 24 \text { hours } \\
\text { MAP at scan }\end{array}$ & $\begin{array}{l}32(20-46) \\
26 \% \%^{\star} \\
14(8-30) \\
16 \% \%^{\star} \\
7(2-12)^{\star} \dagger\end{array}$ & $\begin{array}{l}30(24-49) \\
59 \% \%^{\star} \\
10(6-58) \\
42 \% \star \\
9(6-15)^{\star}\end{array}$ & $\begin{array}{l}31(22-35) \\
72 \% \\
18(8-50) \\
85 \% \star \\
10(7-19) \dagger\end{array}$ \\
\hline
\end{tabular}

Figures are medians (range) and incidence, ${ }^{\star}+$ significant difference between pairings: $\mathrm{P}<0 \cdot 05$.

clear interatrial shunt could be seen on colour flow Doppler mapping, this was classified as no significant atrial shunt.

\section{Formulae}

The following formulae were used in the cardiac calculation package incorporated into the software of the Accuson 128/XP10:

(1) Right and left ventricular stroke volume $=$ Velocity time integral $\times(3 \cdot 1416 \times$ [Outflow diameter $2 / 4$ ])

(2) Right and left ventricular output $=$ Stroke volume $\times$ Heart rate/Bodyweight $(\mathrm{kg})$.

\section{CLINICAL PARAMETERS}

For each infant on each of the echocardiographic study days, hourly measures of fractional inspired oxygen concentration $\left(\mathrm{FIO}_{2}\right)$ and mean airway pressure (MAP) were recorded from the continuous display on the ventilator. MAP and $\mathrm{FIO}_{2}$ were also recorded at the time of echocardiography.

Surfactant therapy was given as 2 doses of Exosurf, 12 hours apart, as rescue therapy when the alveolar to arterial oxygen ratio was less than $0 \cdot 22$. Blood pressure was supported if the mean blood pressure fell consistently below the infant's gestation in weeks. Human albu$\min 5 \%(10 \mathrm{ml} / \mathrm{kg})$ was given initially, followed by dopamine (or occasionally dobutamine at the clinician's discretion) at $10 \mu \mathrm{g} / \mathrm{kg} /$ minute, increasing in steps to a maximum of 20 $\mu \mathrm{g} / \mathrm{kg} / \mathrm{minute}$ if blood pressure did not improve. Further boluses of 5\% albumin were given, at the attending clinician's discretion, if hypotension persisted.

\section{CLASSIFICATION OF RESPIRATORY DISEASE SEVERTTY}

The infants were divided up into groups on the basis of their early oxygen requirements along similar lines to that described by Walther et al ${ }^{13}$ except we used mean $\mathrm{FIO}_{2}$ over the first 24 hours rather than maximum $\mathrm{FIO}_{2}$. The infants were classified as mild $(n=77)$ when the mean $\mathrm{FIO}_{2}$ was less than $0 \cdot 5$, moderate to severe $(n=36)$. when mean $\mathrm{FIO}_{2}$ was more than $0 \cdot 5$, and fatal $(n=7)$ when death resulted directly from the early acute phase of the respiratory disease. Median age at death of these seven infants was day 3 (range 1-9). The fatal group did not include nine infants who subsequently died from non-respiratory causes, seven died from infection, and two from intraventricular haemorrhage. The respiratory diagnosis in the mild group was hyaline membrane disease in 46 , immature lung in 27 , and pneumonia in four; the moderate/severe group all had hyaline membrane disease; and in the fatal group, six had hyaline membrane disease and one had pulmonary hypoplasia.

The study was approved by the Royal Prince Alfred Hospital Ethics Committee and infants were studied with the consent of their parents unless there was a clinical indication for an echocardiogram.

Statistical analysis was done with a computer statistics package (SPSSPC, SPSS Inc, Chicago, Illinois) using stepwise multilinear regression analysis, Mann Whitney $U$ test, $\chi^{2}$ test, and Kruskal-Wallis analysis of variance for non-parametric data. $P$ values of less than 0.05 were accepted as significant.

\section{Results}

INITIAL STUDIES ( $<36$ HOURS)

The initial studies on all 120 infants were analysed, all of which had been carried out within the first 36 hours. Table 1 shows the clinical parameters for the three respiratory severity groups in these early scans. There were no differences in gestation, age at scan, or average mean blood pressure between the three groups, but the differences in mean $\mathrm{FIO}_{2}$ were significant, $P<0.0001$. The mild group had significantly lower MAP at the time of the scan than the other two groups $(P<0 \cdot 001)$. Plasma volume expanders and inotropes were used more commonly with worse respiratory disease. Thirty one of the 33 infants in whom inotropes were used were receiving them at the time of echocardiography. Twenty eight were receiving dopamine and three dobutamine at a dose of at least $10 \mu \mathrm{g} / \mathrm{kg} /$ minute. In one infant in the moderate/severe group and one in the fatal group, inotropes were started after the initial echocardiogram.

Echocardiographic measurements are compared in table 2 . Median RVO was significantly lower with increasing respiratory severity groups $(P<0.02)$, and the proportion with RVO less than $150 \mathrm{ml} / \mathrm{kg} /$ minute increased significantly with increasing respiratory disease severity. Median LVO was also lower and the proportion with an LVO $<150 \mathrm{ml} / \mathrm{kg} /$ minute increased with worsening respiratory disease. For LVO, the difference between the mild and moderate/severe groups was not significant but was significant for the fatal group $(\mathrm{P}<0.0001)$. While disparities between the ventricular outputs occurred in both directions as a result of shunts, the influence of ductal shunting tended to dominate, with $\mathrm{LV}$ output more likely to exceed RV output (fig 1). In 13 (11\%) infants, as a result of ductal shunting, LV output was within the normal range while RV output was below the normal range. In seven $(6 \%)$ babies, the reverse was the case due to atrial shunting (fig 1). Median LV ejection fraction and TPV:RVET did not differ across the groups.

The proportion of each group with a closed duct and the median diameter of the patent 
Table 2 Cardiovascular parameters on early echocardiogram according to respiratory disease severity

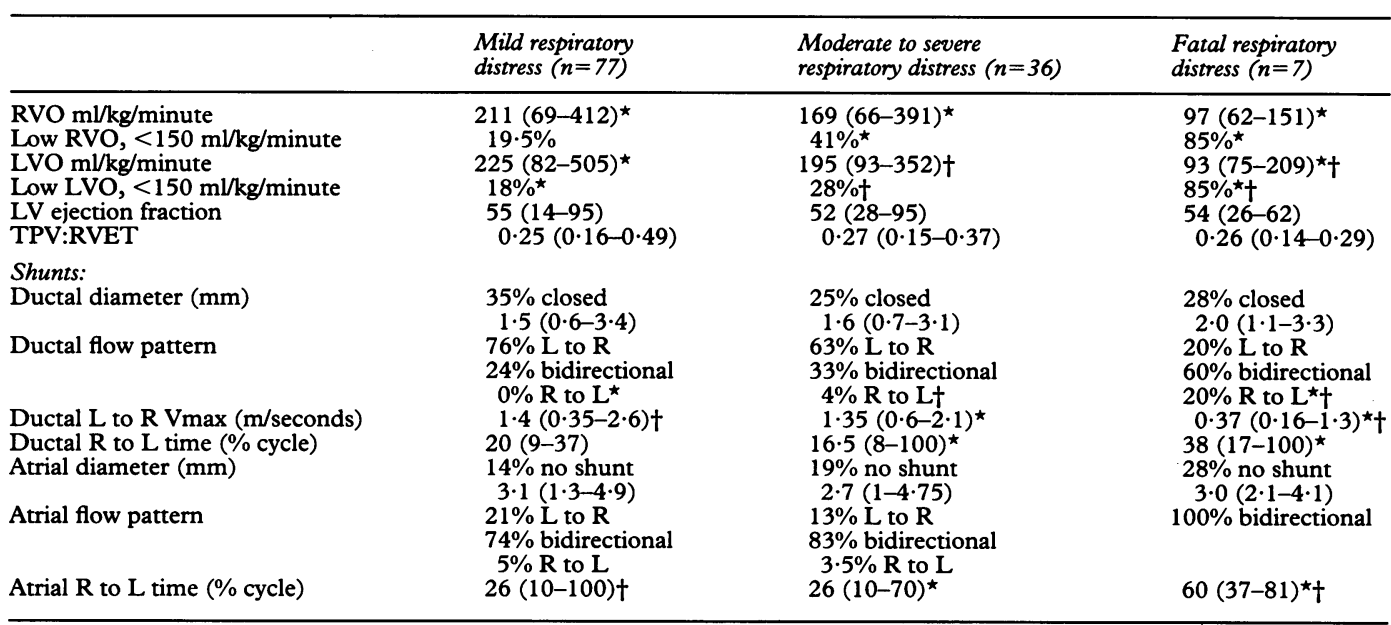

Figures are medians (range) and incidence. Vmax is maximum velocity, $R$ to $L$ is right to left and $L$ to $R$ is left to right.

$\star+$ significant difference between pairings: $P<0 \cdot 05$.

ducts did not differ significantly. The fatal group had significantly lower maximum left to right ductal shunt velocity and significantly more infants with bidirectional or right to left ductal shunting with significantly more of the cardiac cycle occupied by right to left shunting $(P<0.05)$. The differences between the mild and moderate/severe groups were again not significant. The proportion of each group with no atrial shunt and the colour Doppler diameter of the atrial shunt in those with foramen ovale incompetence did not differ significantly. The proportion of each group with bidirectional or right to left atrial shunting was also not significantly different, but the proportion of the cardiac cycle occupied by right to left shunt was significantly longer in the fatal group $(\mathbf{P}<0.002)$.

The influences on RVO and LVO were examined in a stepwise multilinear regression analysis which included the initial study on all 120 infants.

\section{Right ventricular output}

This was analysed as a dependent variable against gestation, postnatal age at scan, inotrope use and volume of plasma expander given on the day of the scan, MAP at the time of the scan, $\mathrm{FIO}_{2}$ at the time of the scan, left ventricular ejection fraction, TPV:RVET, diameter of the ductus arteriosus (a measure of ductal shunt size), diameter of the atrial shunt (a measure of atrial shunt size), and LVO. The three factors incorporated into the equation as

Figure 1 This graph plots $L V O$ against $R V O$ in the initial studies done within the first 36 postnatal hours on all 120 infants. The dotted lines mark the lower limit of normal for each ventricular output.

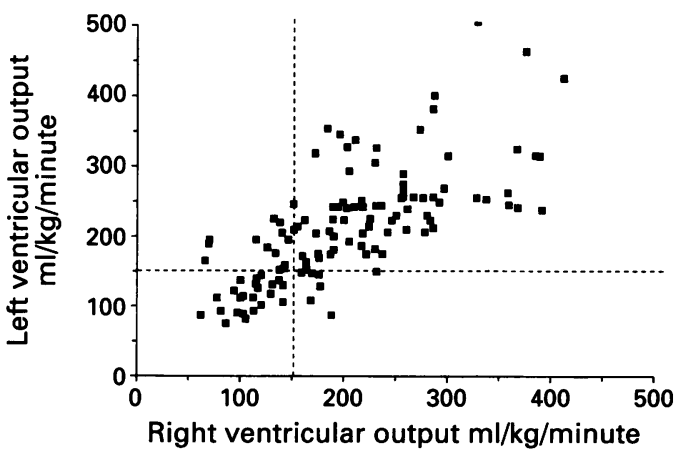

significant were, in step number order, increasing $\mathrm{LVO}$ as a positive influence $(P<0.0001)$, increasing ductal diameter as a negative influence $(P<0.0001)$, and increasing atrial shunt diameter as a positive influence $(P<0.003)$; multiple $\mathrm{r}=0 \cdot 79$.

\section{Left ventricular output}

This was analysed against the same variables including RVO. The three factors incorporated as significant were increasing $R V O$ as a positive influence $(P<0.0001)$, increasing ductal diameter as a positive influence $(P<0.0001)$, increasing atrial shunt diameter as a negative influence $(P<0.0001)$; multiple $r=0.81$.

\section{LONGITUDINAL STUDIES}

Forty nine of the infants were studied daily for each of the first four days. Only one of the infants in the fatal RDS group survived longer than 48 hours so numbers were insufficient to describe longitudinal changes for this group. The longitudinal changes in the parameters described above are shown for the mild group (table 3) and the moderate/severe group (table 4). Median MAP at the time of the scan fell over the first four days, significantly so in the moderate/severe group. In both groups median RVO increased significantly with time and by day 4 no infant had an RVO of $<150$ $\mathrm{ml} / \mathrm{kg} /$ minute. The increase in LVO seen with time did not reach significance for either group. Outputs below $150 \mathrm{ml} / \mathrm{kg} /$ minute were not seen after day 1 in the mild group.

Ductal closure occurred at a similar rate in the two groups and for both groups the diameter of the patent ducts trended smaller. Four infants in each group received indomethacin to close a patent ductus arteriosus during the first four days. Only one infant had a pure right to left shunt on day 1 . Bidirectional shunting occurred in a minority of both groups, the right to left component of this pattern usually occupied only a small proportion of the cardiac cycle. Bidirectional shunting was not seen after day 2 . The predominant pattern of atrial shunting was 
Table 3 Longitudinal cardiovascular changes in mild respiratory distress ${ }^{\star}$

\begin{tabular}{|c|c|c|c|c|c|}
\hline & Day $1(n=20)$ & Day $2(n=22)$ & Day $3(n=25)$ & Day $4(n=20)$ & $P$ value \\
\hline $\begin{array}{l}\text { Age at scan (hours) } \\
\text { MAP at scan }\end{array}$ & $\begin{array}{c}18 \cdot 5(7-24) \\
7(2-11)\end{array}$ & $\begin{array}{c}38(25-47) \\
7 \cdot 5(4-12)\end{array}$ & $\begin{array}{l}62(49-72) \\
6(0-13)\end{array}$ & $\begin{array}{c}83(73-95) \\
6(0-12)\end{array}$ & $0 \cdot 2$ \\
\hline $\begin{array}{l}\text { Ventricular outputs: } \\
\text { RVO } \mathrm{ml} / \mathrm{kg} / \mathrm{minute} \\
\text { RVO }<150 \mathrm{ml} / \mathrm{kg} / \text { minute } \\
\text { LVO } \mathrm{ml} / \mathrm{kg} / \mathrm{minute} \\
\text { LVO }<150 \mathrm{~m} / \mathrm{kg} / \text { minute } \\
\text { LV ejection fraction } \\
\text { TPV:RVET }\end{array}$ & $\begin{array}{l}202(102-376) \\
15 \% \\
233(144-463) \\
5 \% \\
58(31-71) \\
0 \cdot 25(0 \cdot 19-0 \cdot 32)\end{array}$ & $\begin{array}{l}239(160-300) \\
0 \% \\
241(150-400) \\
0 \% \\
56(32-95) \\
0.25(0 \cdot 16-0 \cdot 33)\end{array}$ & $\begin{array}{l}240(187-375) \\
0 \% \\
239(154-446) \\
0 \% \\
58(25-79) \\
0.32(0.2-0.33)\end{array}$ & $\begin{array}{l}287(166-385) \\
0 \% \\
282(170-489) \\
0 \% \\
56(37-79) \\
0.27(0 \cdot 21-0 \cdot 35)\end{array}$ & $\begin{array}{l}0.008 \\
0.26 \\
0.88 \\
0.03\end{array}$ \\
\hline $\begin{array}{l}\text { Shunts: } \\
\text { Ductal diameter (mm) } \\
\text { Ductal shunt patterns }\end{array}$ & $\begin{array}{l}35 \% \text { closed } \\
2 \cdot 0(1 \cdot 1-3 \cdot 2) \\
85 \% \mathrm{~L} \text { to } \mathrm{R} \\
15 \% \text { bidirectional }\end{array}$ & $\begin{array}{l}50 \% \text { closed } \\
1 \cdot 5(1 \cdot 1-3 \cdot 5) \\
81 \% \mathrm{~L} \text { to } \mathrm{R} \\
19 \% \text { bidirectional }\end{array}$ & $\begin{array}{l}68 \% \text { closed } \\
1 \cdot 85(1 \cdot 1-2 \cdot 5) \\
100 \% \text { L to R }\end{array}$ & $\begin{array}{l}65 \% \text { closed } \\
1 \cdot 5(1 \cdot 3-3 \cdot 3) \\
100 \% \mathrm{~L} \text { to } \mathrm{R}\end{array}$ & $0 \cdot 85$ \\
\hline $\begin{array}{l}\mathrm{L} \text { to } \mathrm{R} \text { ductal } \mathrm{Vmax}(\mathrm{m} / \mathrm{second}) \\
\text { Ductal } \mathrm{R} \text { to } \mathrm{L} \text { time } \% \text { of cycle } \\
\text { Atrial diameter (mm) }\end{array}$ & $\begin{array}{l}1 \cdot 37(0 \cdot 8-2 \cdot 1) \\
24(24) \\
20 \% \text { no shunt }\end{array}$ & $\begin{array}{l}1 \cdot 38(0 \cdot 8-1 \cdot 8) \\
15(8-22) \\
14 \% \text { no shunt }\end{array}$ & $\begin{array}{l}1.66(0.95-2 \cdot 8) \\
16 \% \text { no shunt }\end{array}$ & $1 \cdot 61(0 \cdot 38-2 \cdot 1)$ & 0.38 \\
\hline Atrial flow pattern & $\begin{array}{l}3 \cdot 25(1 \cdot 3-4 \cdot 6) \\
20 \% \mathrm{~L} \text { to } \mathrm{R} \\
66 \% \text { bidirectional } \\
13 \% \mathrm{R} \text { to } \mathrm{L}\end{array}$ & $\begin{array}{l}2 \cdot 56(1 \cdot 3-4 \cdot 2) \\
26 \% \text { L to } \mathrm{R} \\
7.4 \% \text { bidirectional }\end{array}$ & $\begin{array}{l}2 \cdot 8(1 \cdot 6-4 \cdot 5) \\
21 \% \mathrm{~L} \text { to } \mathrm{R} \\
79 \% \text { bidirectional }\end{array}$ & $\begin{array}{l}2 \cdot 56(0 \cdot 6-4 \cdot 6) \\
25 \% \text { L to } R \\
75 \% \text { bidirectional }\end{array}$ & $0 \cdot 12$ \\
\hline Atrial $\mathbf{R}$ to $\mathrm{L}$ time $\%$ cardiac cycle & $26(14-100)$ & $24(16-33)$ & $24(14-41)$ & $27(6-46)$ & 0.8 \\
\hline
\end{tabular}

^Figures are medians (range) and incidence. Statistics achieved with Kruskal-Wallis analysis of variance.

bidirectional throughout the first four days, though pure left to right shunting was slightly more common in the mild/moderate group. Pure right to left atrial shunt was seen in two infants with mild respiratory distress on day 1 and one severe infant on day 2 . The median right to left proportion of this atrial shunting did not differ with time or between the two groups.

\section{MULTILINEAR REGRESSION ANALYSIS ON THE} LONGITUDINAL STUDIES

The influences on RVO and LVO were examined in a stepwise multilinear regression analysis, including the 174 studies done on the 49 infants who were studied longitudinally.

\section{Right ventricular output}

This was analysed as a dependent variable against gestation, postnatal age at scan, inotrope use and volume of plasma expander given on the day of the scan, MAP at the time of the scan, $\mathrm{FIO}_{2}$ at the time of the scan, left ventricular ejection fraction, TPV:RVET, diameter of the ductus arteriosus (a measure of ductal shunt size), diameter of the atrial shunt (a measure of atrial shunt size), and LVO. The four factors incorporated into the equation as significant were, in step number order, increasing LVO as a positive influence $(P<0.0001)$, increasing ductal diameter as a negative influence $(P<0.0001)$, increasing atrial shunt diameter as a positive influence $(P<0.0002)$, and increasing MAP as a negative influence $(\mathrm{P}<0.001)$; multiple $\mathrm{r}=0.78$.

\section{Left ventricular output}

This was analysed against the same variables including RVO. The three factors incorporated as significant were increasing $\mathrm{RVO}$ as a positive influence $(P<0.0001)$, increasing ductal diameter as a positive influence $(P<0.0001)$, and increasing atrial shunt diameter as a negative influence $(P<0 \cdot 0004)$; multiple $r=0 \cdot 76$.

\section{Discussion}

Few studies have examined LVO serially in a cohort of sick preterm infants and none, to our knowledge, have examined this together with RVO. Doppler echocardiographic means of

Table 4 Longitudinal cardiovascular changes in moderate/severe respiratory distress ${ }^{\star}$

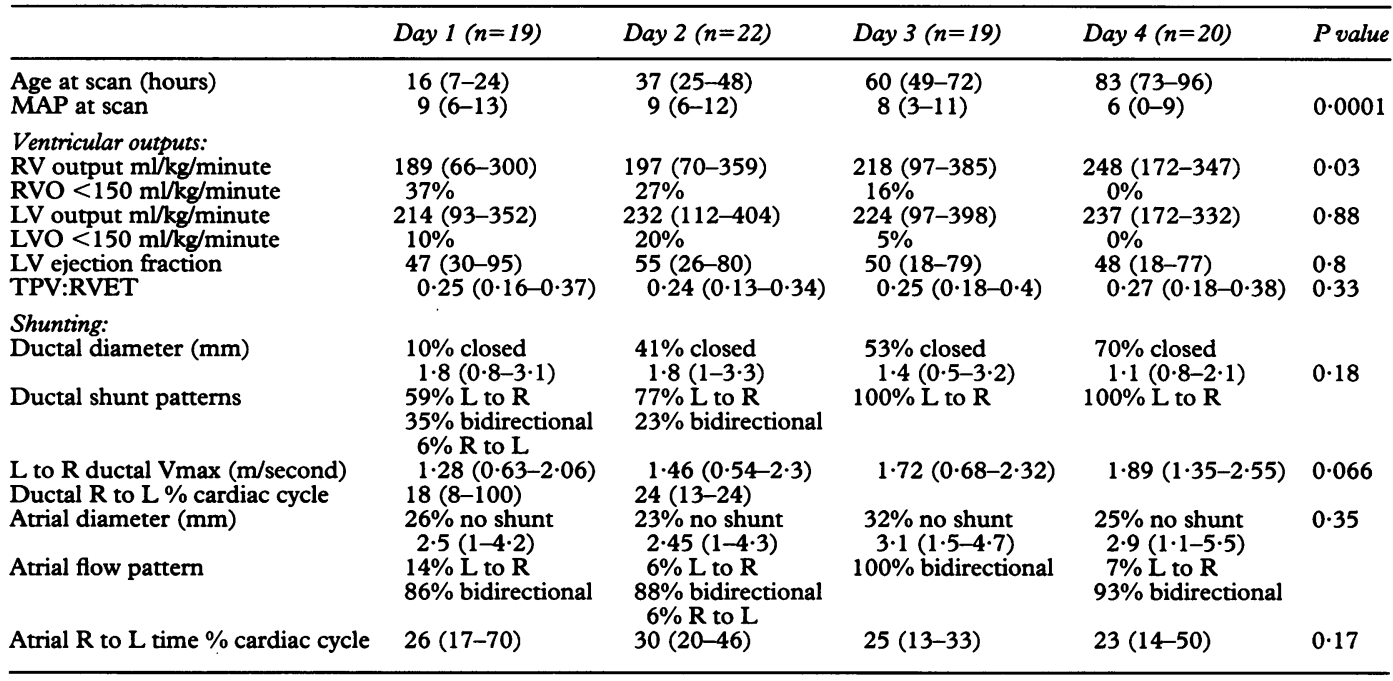

^Figures are medians (range) and incidence. Statistics with Kruskal-Wallis analysis of variance. 
assessing LVO have been validated over a wide age range and have shown a consistently close correlation with invasive methods of assessing cardiac output. ${ }^{1415}$ While concerns have been raised about the interpretation of Doppler derived cardiac output in individual critically ill infants, ${ }^{16}$ it remains the best validated and most applicable methodology for the study of preterm newborns. The use of Doppler echocardiography to measure RVO is less well validated in infants, but close correlations have been found in older subjects and animals, ${ }^{17} 18$ and we have shown a close correlation between Doppler measures of RVO and LVO in infants in whom there were no shunts. ${ }^{23}$

An important finding in this study is the wide range of cardiac outputs found in these infants. The extent of low cardiac output in these early stages has not, to our knowledge, been documented before. Different methodologies for measuring aortic diameter confound the definition of a low ventricular output in newborns, but term babies usually have an LVO between 200 and $300 \mathrm{ml} / \mathrm{kg} /$ minute $^{19-22}$ We chose $150 \mathrm{ml} / \mathrm{kg} /$ minute as our lower limit of normal, as measurements below this were unusual in two previous studies of well preterm infants, which used the same methodology as this study. 622

The primary aim in measuring cardiac output is to derive an index of systemic perfusion. In reality, neither ventricular output does this accurately in all cases. LVO will be the sum of systemic flow and any left to right flow at ductal level and RVO is the sum of the systemic venous return and any left to right atrial shunt. In the few instances where there is right to left shunting, the situation is even more complex. Atrial shunts, while they can be large, tend to be smaller than ductal shunts, ${ }^{23}$ thus RVO showed low systemic blood flow more often than LVO. RVO fell significantly with worsening respiratory disease severity while LVO was only significantly lower in the fatal group. Thus these data would suggest a proportion of ventilated preterm infants have suboptimal early systemic blood flows which would not be detected if LVO alone was measured. The incidence of low outputs increased with worse respiratory disease and decreased with age, outputs below 150 $\mathrm{ml} / \mathrm{kg} /$ minute were not seen after day 3 .

The other finding of this study is that the determinants of cardiac output are multifactorial. Poor preterm cardiac output has been seen primarily as a product of an immature myocardium. ${ }^{23} \mathrm{LV}$ ejection fraction, admittedly a broad measure of myocardial function in the preterm infant, ${ }^{24}$ was not significantly associated with either ventricular output. The significant negative influences on RVO were increasing ductal diameter and higher MAP, and negative influences on LVO were increasing atrial shunt diameter and earlier postnatal age. The predominantly left to right pattern of ductal shunting will reduce RVO and atrial shunting will reduce LVO by shunting blood from the systemic back to the pulmonary circulations. ${ }^{4}$ This effect is apparent even at this early postnatal time.
The negative impact of worse respiratory disease was significantly related to MAP. The negative impact of positive pressure ventilation on cardiac output has been consistently demonstrated in older people and animals. ${ }^{25-27}$ At low pressures, it is felt that this negative influence is mediated primarily through reduced systemic venous return but that, at very high pressures, direct effects on pulmonary vascular resistance, and myocardial function become important. ${ }^{27}$ In the sickest infants all these factors were probably important. MAP was often very high, hypoxia and acidosis were common, and high pulmonary artery pressure was suggested by lower ductal shunt velocities. But when comparing the mild and moderate/severe groups of infants, there was no significant difference in pulmonary artery pressure between the two groups, measured by either TPV:RVET or ductal shunt velocity, nor was there any difference in $\mathrm{LV}$ ejection fraction to account for the difference in incidence of low outputs. By exclusion, this might point to reduced systemic venous return as an important limiting factor. Both ventricles also show an ability to increase substantially their outputs when the preload of a ventricle is increased by a ductal or atrial shunt, confirming a degree of myocardial reserve. We speculate that the effect of positive pressure ventilation in reducing systemic venous return, and so cardiac output, may be as important in preterm infants as it has been recognised to be in adults. ${ }^{25} 27$ There are few studies on the effect of ventilation on cardiac output in preterm infants. Hausdorf and

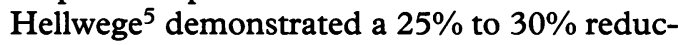
tion in ventricular stroke and minute volumes, with no effect on blood pressure, by increasing PEEP from zero to $8 \mathrm{~cm} \mathrm{H}_{2} \mathrm{O}$ in a group of preterm infants. The clinical importance of this is that if by improving arterial oxygenation we reduce perfusion, tissue oxygenation will be compromised. Trang et a ${ }^{28}$ suggested that this occurs at PEEP levels above $6 \mathrm{~cm} \mathrm{H}_{2} \mathrm{O}$ in preterm infants.

Therapeutic efforts to improve systemic perfusion usually involve intravascular volume expansion and/or inotropes. Volume expansion does not improve blood pressure in many preterm infants and has inconsistent effects on LVO. ${ }^{29} 30$ But there is some evidence from adults $^{25}$ and one study in the preterm newborn $^{31}$ to suggest that volume expansion can correct some of the preload deficit which results from positive pressure ventilation and improve cardiac output in the short term. Inotropes, while improving blood pressure, have not been shown to consistently improve LVO in non-asphyxiated preterm infants. ${ }^{29} 32$ Roze $e t a l^{32}$ actually demonstrated a reduction in LVO in response to dopamine which was most pronounced in those with the worst lung disease. If systemic venous return rather than myocardial dysfunction were the main problem, inotropes might be expected to have little effect on ventricular outputs. In this study low outputs were more common with worse respiratory disease, despite the increased use of inotropes. Almost all the babies given 
inotropes were receiving them at the time of the scan and averaged mean blood pressure was not significantly different across the groups. This would be in line with the observation of Roze, ${ }^{32}$ that dopamine is better at improving blood pressure than LVO. Our data suggest that the two negative influences on ventricular outputs over which we have some therapeutic control are MAP and ductal shunting.

The outputs from each ventricle relate closely to the other, although the correlation between the two is not that strong ( $r=0.68)$, reflecting shunting. These data highlight that each point of the circulation can have an influence on the other parts and that in the complex flux of the preterm heart, ventricular output measures will often not be representative of systemic flow. Single site measures of flow will be subject to misinterpretation. Walther et $a l^{13}$ suggested that low flow in the left pulmonary artery in infants with severe HMD was due to right to left ductal shunting. The present data have shown that often this finding would be due to low total right heart output, not just ductal shunting. Although right to left ductal shunting, usually as part of a bidirectional pattern, does occur in the early postnatal period, it was common, as was right to left atrial shunting, only in those with fatal respiratory disease. For other infants, right to left intracardiac shunting is uncommon and transient.

In conclusion, both ventricular outputs are very variable in the early postnatal period. Low outputs are common and are significantly associated with worse lung disease and large left to right intracardiac shunts. A clearer understanding of this complex haemodynamic situation is important to permit appropriate interpretation of studies of blood flow to various organs, particularly the brain, and to enable clinicians to rationalise interventions designed to support systemic blood flow in sick preterm infants.

1 Friedman WF. Intrinsic physiological properties of the developing heart. Progr Cardiovasc Dis 1972; 15: 87-111.

2 Evans $\mathrm{N}$, Iyer P. Incompetence of the foramen ovale in preterm infants supported by mechanical ventilation. f Pediatr 1994; 125: 786-92.

3 Evans N, Iyer P. Assessment of ductus arteriosus shunt in preterm infants supported by mechanical ventilation: Effects of interatrial shunting. $\mathcal{f}$ Pediatr 1994; 125: 778-85.

4 Clyman RI, Mauray F, Heymann MA, Roman C. Cardiovascular effects of patent ductus arteriosus in preterm lambs with respiratory distress. $\mathcal{f}$ Pediatr 1987; 111: $579-87$

5 Hausdorf $\mathrm{G}$, Hellwege $\mathrm{HH}$. Influence of positive end-expiratory pressure on cardiac performance in premature infants: a Doppler-echocardiographic study. Crit Care Med 1987; 15: 661-4

6 Walther FJ, Kim DH, Ebrahimi M, Siassi B. Pulsed Doppler measurement of left ventricular output as early predictor of symptomatic patent ductus arteriosus in very preterm infants. Biol Neonate 1989; 56: 121-8.

7 Mellander M, Larsson LE. Effects of left-to-right ductus shunting on left ventricular output and cerebral blood flow velocity in 3-day-old preterm infants with and without severe lung disease. $\mathcal{f}$ Pediatr 1988; 113: 101-9.
8 Sahn DJ, DeMaria A, Kisslo J, Weyman A. Recommendations regarding quantitation in $M$-mode echocardiography: Results of a survey of echocardiographic measurements. Circulation 1978; 58: 1072-83.

9 Evans NJ, Archer LN. Doppler assessment of pulmonary artery pressure and extrapulmonary shunting in the acute phase of hyaline membrane disease. Arch Dis Child 1991; 66: 6-11.

10 Sholler GF, Celermajer JM, Whight CM, Bauman AE Echo Doppler assessment of cardiac output and its relation to growth in normal infants. Am $\mathcal{F}$ Cardiol 1987; 60: 1112-6.

11 Mandelbaum Isken VH, Linderkamp O. Cardiac output by pulsed Doppler in neonates using the apical window. Pediatr Cardiol 1991; 12: 13-6.

12 Hiraishi S, Agata Y, Saito K, Oguchi K, Misawa H, Fujino $\mathrm{N}$, et al. Interatrial shunt flow profiles in newborn infants: a colour flow and pulsed Doppler echocardiographic a colour flow and pulsed Dopple
study. $B r$ Heart $\mathcal{f} 1991 ; 65: 41-5$.

13 Walther FJ, Benders MJ, Leighton JO. Persistent pulmonary hypertension in premature neonates with severe respiratory distress syndrome. Pediatrics 1992; 90 899-904.

14 Alverson DC, Eldridge M, Dillon T, Yabek SM, Berman WJ. Noninvasive pulsed Doppler determination of cardiac output in neonates and children. $\mathcal{F}$ Pediatr 1982; 101 46-50.

15 Mellander M, Sabel KG, Caidahl K, Solymar L, Eriksson B. Doppler determination of cardiac output in infants and children: comparison with simultaneous thermodilution. Pediatr Cardiol 1987; 8: 241-6.

16 Notterman DA, Castello FV, Steinberg C, Greenwald BM O'Loughlin JE, Gold JP. A comparison of thermodilution and pulsed Doppler cardiac output measurement in critically ill children. F Pediatr 1989; 115: 554-60.

17 Stewart WJ, Jiang L, Mich R, Pandian N, Guerrero JL Weyman AE. Variable effects of changes in flow rate through the aortic, pulmonary and mitral valves on valve area and flow velocity: impact on quantitative Dopple flow calculations. $\mathcal{F}$ Am Coll Cardiol 1985; 6: 653-62.

18 Sajkov D, Cowie RJ, Bradley JA, Mahar L, McEvoy RD. Validation of new pulsed Doppler echocardiographic techniques for assessment of pulmonary hemodynamics. techniques for assessment

19 Agata Y, Hiraishi S, Oguchi K, Misawa H, Horiguchi Y, Fujino $\mathrm{N}$, et al. Changes in left ventricular output from fetal to early neonatal life. $\mathcal{F}$ Pediatr $1991 ; 119$ : 441-5.

20 Hirsimaki H, Kero P, Wanne O, Erkkola R, Makoi Z. Doppler-derived cardiac output in healthy newborn infants in relation to physiological patency of the ductus arteriosus. Pediatr Cardiol 1988; 9: 79-83.

21 Walther FJ, Siassi B, Ramadan NA, Ananda AK, Wu PY. Pulsed Doppler determinations of cardiac output in neonates: normal standards for clinical use. Pediatrics 1985; 76: 829-33.

22 Alverson DC, Eldridge MW, Johnson JD, Aldrich $M$ Angelus $\mathrm{P}$, Berman WJ. Noninvasive measurement of carAngelus $P$, Berman $W$. Noninvasive measurement of cardiac output in healthy preterm and

23 Gill AB, Weindling AM. Echocardiographic assessment of cardiac function in shocked very low birthweight infants Arch Dis Child 1993; 68: 17-21.

24 Lee LA, Kimball TR, Daniels SR, Khoury P, Meyer RA Left ventricular mechanics in the preterm infant and their effect on the measurement of cardiac performance. F Pediatr 1992; 120: 114-9.

25 Dhainaut JF, Devaux JY, Monsallier JF, Brunet F, Villemant D, Huyghebaert MF. Mechanisms of decreased left ventricular preload during continuous positive pressure ventilation in ARDS. Chest 1986; 90: 74-80.

26 Hening RJ. Effects of positive end-expiratory pressure on the right ventricle. $f$ Appl Physiol 1986; 61: 819-26.

27 Biondi JW, Schulman DS, Soufer R, Matthay RA Hines RL, Kay HR, et al. The effect of incremental positive end-expiratory pressure on right ventricula hemodynamics and ejection fraction. Anesth Analges 1988; 67: 144-51.

28 Trang TT, Tibballs J, Mercier JC, Beaufils F. Optimization of oxygen transport in mechanically ventilated newborns using oximetry and pulsed Doppler-derived cardiac output. Crit Care Med 1988; 16: 1094-7.

29 Rennie JM. Cerebral blood flow velocity variability after cardiovascular support in premature babies. Arch Dis Child 1989; 64: 897-901.

30 Gill AB, Weindling AM. Randomised controlled trial of plasma protein fraction versus dopamine in hypotensive very low birthweight infants. Arch Dis Child 1993; 69: 284-7.

31 Maayan C, Eyal F, Mandelberg A, Sapoznikov D, Lewis BS Effect of mechanical ventilation and volume loading on lef ventricular performance in premature infants with respiratory distress syndrome. Crit Care Med 1986; 14: 858-60.

32 Roze JC, Tohier C, Maingueneau C, Lefevre M, Mouzard A. Response to dobutamine and dopamine in the hypotensive very preterm infant. Arch Dis Child 1993; 69: 59-63. 